\title{
Current Status, Development Trend and Key Technology Analysis of Space Laser Communication
}

\section{Zhong Chunxiao}

Institute of Technology, East China Jiaotong University, Nanchang, Jiangxi, China

Keywords: space laser communication; current status; development trend

Abstract: This paper starts from domestic and foreign current status of space laser communication, and analyzes the development trend and key technology of space laser communication.

\section{Domestic and Foreign Current Status of Space Laser Communication}

The domestic and foreign current status of space laser communication is analyzed in foreign airborne and ground laser communication, and foreign space laser communication.

\subsection{Foreign airborne and ground laser communication}

The technological achievements of foreign space laser communication are shown in Table 1.

Table 1 The technological achievements of foreign space laser communication

\begin{tabular}{|c|c|c|c|c|c|}
\hline Link type & system & Carrying terminal & nation & time & speed \\
\hline \multirow[t]{3}{*}{$\begin{array}{l}\text { Satellite and } \\
\text { ground }\end{array}$} & SLS & $\begin{array}{c}\text { International Space Station } \\
\text { and North Caucasus } \\
\text { Ground Station }\end{array}$ & Russia & 2012 & $125 \mathrm{Mbit} / \mathrm{s}$ \\
\hline & LLCD & $\begin{array}{c}\text { Lunar environment } \\
\text { detector and ground station }\end{array}$ & America & 2013 & $\begin{array}{l}\text { 收 622Mbit/s } \\
\text { 发 20Mbit/s }\end{array}$ \\
\hline & OPALS & $\begin{array}{c}\text { International Space Station } \\
\text { and Whitewood Ground } \\
\text { Station }\end{array}$ & America & 2014 & 50Mbit/s \\
\hline $\begin{array}{l}\text { Satellite and } \\
\text { space }\end{array}$ & LOLA & $\begin{array}{l}\text { Artemis Satellite and } \\
\text { Mysterious } 20 \text { airplane }\end{array}$ & France & 2006 & 50Mbit/s \\
\hline \multirow[t]{2}{*}{ satellites } & LCTSX & $\begin{array}{l}\text { TerraSAR-X Satellite and } \\
\text { NFIRE Satellite }\end{array}$ & $\begin{array}{l}\text { Germany } \\
\text { and } \\
\text { America }\end{array}$ & 2008 & 5.65Gbit/s \\
\hline & EDRS & Sentinel 1-Alphasat & Europe & 2014 & 1.8Gbit/s \\
\hline $\begin{array}{l}\text { Space and } \\
\text { space }\end{array}$ & Falcon & Airplane and airplane & America & 2011 & 2.5Gbit/s \\
\hline $\begin{array}{l}\text { Ground and } \\
\text { ground }\end{array}$ & - & $\begin{array}{l}\text { La Palma Island and } \\
\text { Tenerife Island } \\
\end{array}$ & Germany & 2005 & 5.6Gbit/s \\
\hline \multirow[t]{2}{*}{$\begin{array}{l}\text { Space and } \\
\text { ground }\end{array}$} & 一 & $\begin{array}{l}\text { Airship and ground vehicle } \\
\text { terminal } \\
\end{array}$ & America & 2006 & 40Gbit/s \\
\hline & ARGOS & $\begin{array}{l}\text { DLR airplane and ground } \\
\text { station }\end{array}$ & Germany & 2008 & 150Mbit/s \\
\hline
\end{tabular}

\subsection{Domestic space laser communication}

Domestic space laser communication started very late, which is highly emphasized. The experimental link of domestic space laser communication is shown in Table 2. 
Table 2 The experimental link of domestic space laser communication

\begin{tabular}{|c|c|c|c|c|c|}
\hline Link type & $\begin{array}{l}\text { Carrying } \\
\text { terminal }\end{array}$ & Unit & Time & $\begin{array}{l}\text { Communica } \\
\text { tion speed }\end{array}$ & Distance \\
\hline \multirow[t]{4}{*}{$\begin{array}{l}\text { Ground and } \\
\text { ground }\end{array}$} & $\begin{array}{l}\text { Two ground } \\
\text { terminals }\end{array}$ & CETC No. 34 & 2000 & 155Mbit/s & $26 \mathrm{~km}$ \\
\hline & Ship- ground & $\begin{array}{l}\text { Changchun } \\
\text { University of } \\
\text { Science and } \\
\text { Technology }\end{array}$ & 2007 & 300Mbit/s & $20.4 \mathrm{~km}$ \\
\hline & $\begin{array}{l}\text { Two ground } \\
\text { terminals }\end{array}$ & $\begin{array}{c}\text { Wuhan } \\
\text { University }\end{array}$ & 2010 & 7.5Gbit/s & $40 \mathrm{~km}$ \\
\hline & $\begin{array}{l}\text { Two ground } \\
\text { terminals }\end{array}$ & CETC No. 34 & 2014 & 2.5Gbit/s & $5 \mathrm{~km}$ \\
\hline $\begin{array}{l}\text { Satellite and } \\
\text { ground }\end{array}$ & $\begin{array}{c}\text { Ocean } 2 \\
\text { Satellite-gro } \\
\text { und station }\end{array}$ & $\begin{array}{l}\text { Harbin Institute } \\
\text { of Technology }\end{array}$ & 2011 & 504Mbit/s & $2000 \mathrm{~km}$ \\
\hline underwater & $\begin{array}{l}\text { ship-under } \\
\text { water }\end{array}$ & SIOM & 2010 & $10 \mathrm{Kbit} / \mathrm{s}$ & $125 \mathrm{~m}$ \\
\hline $\begin{array}{l}\text { Space and } \\
\text { ground }\end{array}$ & airship_ship & $\begin{array}{l}\text { Changchun } \\
\text { University of } \\
\text { Science and } \\
\text { Technology }\end{array}$ & 2011 & 1.5Gbit/s & $20.8 \mathrm{~km}$ \\
\hline \multirow[t]{2}{*}{$\begin{array}{l}\text { Space and } \\
\text { space }\end{array}$} & $\begin{array}{c}\text { Two } \\
\text { helicopters }\end{array}$ & $\begin{array}{l}\text { Changchun } \\
\text { University of } \\
\text { Science and } \\
\text { Technology }\end{array}$ & 2011 & 1.5Gbit/s & $17.5 \mathrm{~km}$ \\
\hline & $\begin{array}{c}\text { Two-transpor } \\
\text { tation } 12 \\
\text { airplane }\end{array}$ & $\begin{array}{l}\text { Changchun } \\
\text { University of } \\
\text { Science and } \\
\text { Technology }\end{array}$ & 2013 & 2.5Gbit/s & $144 \mathrm{~km}$ \\
\hline
\end{tabular}

\section{Development Trend of Space Laser Communication}

At present, development trend of space laser communication is indicated in high speed, network, multi-purpose, integration and multi-spectrum.

\subsection{High speed}

Space laser communication is developing at a very fast pace. Specifically, first, as early as 2012, ESA proposed a satellite system. The satellites carried by the two payloads can reach a communication rate of $1.8 \mathrm{Gbit} / \mathrm{s}$ at a distance of 40,000 km. Second, in 2014, Japan's Yuhang Discovery Bureau plans to launch a transit satellite in 2019, with an expected communication rate of $1.8 \mathrm{Gbit} / \mathrm{s}$; Third, in 2013, the United States proposed LCRD, and the satellite will be launched in 2016 with a communication rate of $2.8 \mathrm{Gbit} / \mathrm{s}$; Fourth, the US laser communication company set up an ultra-high-speed laser communication network within four years. The network has 8 satellites and 48 ground stations, and the total communication rate can reach $200 \mathrm{Gbit} / \mathrm{s}$

One of the advantages of high-speed spatial laser communication is that it can realize large-capacity real-time information transmission. The main difficulty lies in the difficulty in realizing the realization of high-power light source output and communication low bit rate. Therefore, the difficulties can be solved by combining the photovoltaic technology. 


\subsection{Network}

At present, space laser communication is one-to-one, which directly affects communication relay, networking and its applications. It can be said that network is the most important development trend of space laser communication. First, as early as 2012, Japan proposed a two-layer low-orbit low-altitude satellite system networking plan; second, in 2003, the United States proposed the TSAT program, and many of the laser communication technologies in the program are still in the process of development. The networking mainly includes space-based laser communication network, air-based laser communication network, space-to-ground laser access network, and ground-to-sea laser emergency network.

The main advantage of laser communication networking is the ability to realize the fast, real-time and secure communication network. However, the technical difficulties are problems such as dynamic topology access and network openness. The main solution is to adopt dynamic routing to solve the access problem and improve the integrated communication protocol.

\subsection{Multi-purpose}

Space laser communication is widely used in communication links such as inter-satellite, satellite and space, space and space, space and ground, and is gradually expanding to deep space and submarine communications. First, as early as 2009, NASA proposed the MLCD program to develop deep-space high-data remote communication with a communication rate of $100 \mathrm{Gbit} / \mathrm{s}$. Second, in 2005, a US technology company launched a potential data exchange and enhancement program.

It can be said that submarine laser communication is an important development field for laser communication, especially in military applications. In general, compared to traditional space laser communication, the advantage of submarine laser communication is that the low frequency rate is high, but the difficulty lies in the need to cross the atmosphere and seawater, and the laser scattering in seawater is very serious. The main solution is to use blue-green laser with better penetrability.

\subsection{Integration}

Space laser communication integration mainly refers to the combination of space laser communication and laser ranging and optical imaging to achieve integration. First, in the US X2000 project, the flight terminal uses shared signal lights with ranging and communication, scientific imaging and laser altimeters. In the second year, in 2005, NASA used the SLR2000 laser range finder as the beacon light for laser communication. Third, in 2013, NASA's LLCD system in the United States, in addition to the laser communication function, was able to measure the ranging flight time to the centimeter.

In the application of integration and development trend of measurement and communication, its main advantage lies in the realization of the combination of ranging and communication. The main difficulty lies in the poor anti-interference ability and weak ranging light energy. Therefore, the main solution is to use the method of ranging and communication common wavelength and modulation dual system.

\subsection{Multi-spectrum}

The multi-spectral laser communication mainly combines the development of multi-spectral directions such as ultraviolet light, visible light, infrared light and radio. The main purpose is to give play to the advantages of different spectrums in the communication system. First, in 2008, American companies realized real-time communication under outdoor sunlight. Second, Japan's Nagaoka University uses visible light communication technology.

\section{Key Technologies of Space Laser Communication}

\subsection{High-quality optical system design technology}

As one of the key technologies of space laser communication technology, high-quality optical system design technology mainly includes near-diffraction limit angle optical system design 
technology, multi-optical axis consistency adjustment technology and high-precision capture alignment tracking technology.

For near-diffraction limit angle optical system design technology, the main difficulty is that the laser beam divergence is about 10,000 times compression, and the high-quality emission of the beam needs to be guaranteed. The technology can realize the emission near-diffraction limit, and the main optical structure is the structure of the phase structure of the large-diameter aspherical spectroscopic system. Then for multi-optical axis consistency adjustment technology, the technical difficulty lies in the high requirements for the consistency of multiple optical axes, mainly using CCD subdivision detection technology. Finally, for high-precision capture alignment tracking technology, the main difficulty lies in the need to assemble a variety of optical components, such as lasers, actuators, etc., and when using materials, lightweight and radiation-resistant materials shall be selected.

\subsection{High-precision capture alignment tracking technology}

The main workflow of high-precision capture alignment tracking technology is to determine the initial area of uncertain capture, capture coarse tracking, perform alignment fine tracking, and realize laser dynamic information communication. The most critical technology in the entire process is to capture coarse tracking and alignment fine tracking. The main difficulty of these two technologies is that the uncertainty area is large and the beam angle is small, so the capture time will be long and the probability will be relatively low. The main solution is to use precision attitude determination and pointing technology and speed vibration compensation technology. However, the main technical difficulty in aligning fine tracking is that the influence of platform vibration is large, then the application of intelligent digital control technology can be applied to improve system robustness.

\subsection{Compensation technology influenced by atmospheric channel}

When the laser beam propagates in the atmosphere, the atmospheric channel has a direct influence on the laser beam, mainly affecting the quality of the laser by attenuating the laser power, which will directly affect the spatial laser communication effect, and may even cause communication failure. In response to the problems, two measures can be taken. First, a wide-range laser light intensity stabilization technique is adopted, which is mainly realized by using an adaptive control algorithm. Then the high-precision real-time wavefront distortion correction technology is adopted, and the main way is to use the Hartmann sensor to achieve thin surface correction.

\subsection{High-speed and high-power launch technology}

High speed and high power are the most important technical requirements of the laser, which can not only effectively remove the background light, but also provide communication functions. The main application techniques of high speed and high power are internal modulation launch technology and external modulation launch technology.

For internal modulation launch technology, the difficulty is that the laser source must meet the requirements of high speed, high quality and high power. The technical approach is to develop high performance seed precursor lasers. For external modulation launch technology, the main difficulty is that the operating point of the bias voltage of the electro-optical modulation crystal is directly changed by the temperature change. The technical approach is to increase the peripheral temperature control feedback circuit, using multi-point side pumping to achieve high power output.

\subsection{High-sensitivity and low-error detection technology}

At present, intensity modulation direct detection technology and coherent detection technology are the two most commonly used detection techniques. For intensity modulation direct detection technology, the main difficulty is strong background interference, difficult signal extraction, and low receiving power. Therefore, the main technical approach is to use automatic gain extraction technology, and thermoelectric refrigeration technology and built-in preamplification technology. Then for coherent detection technology, the main difficulty lies in the narrow line width of light 
source and the high efficiency of mixing. The technical approach is to develop a stable narrow linewidth laser to reduce the mismatch angle and improve the mixing efficiency.

\subsection{One-point to multi-point communication technology}

One-to-many communication technology is a necessary condition for the realization of space laser communication networking with the ability of middle and duplex communication. In general, the principle of one-to-many communication function can be mainly divided into the simple principle, exchange distribution, RF laser combination, and field of view expansion. The technical structure of different kinds of principles is also different. The technical difficulty of the rotating parabolic structure is that the communication range is wide and the utilization of light energy is low. The technical approach is to optimize the splicing structure of the multi-mirror to improve the utilization of light energy. For the three concentric spherical structure, the difficulty lies in the communication of the large field of view and the control of the multi-detector orbit. The main technical approach is to optimize the design of the optical structure and adopt a multi-tracking track design.

\subsection{Platform vibration and compensation technology}

The attitude disturbance and orbital positioning accuracy of the platform will affect the initial orientation of the visual axis of the laser communication system and the open-loop capture uncertain area, which will affect the capture time and capture probability. Compared with different platforms, the technical difficulties of different platforms will also have certain differences, such as the diversification of platform attitude parameters and the complexity of platform vibration factors. Then the main technical approach is to pass the low-frequency disturbance, and adopt the attitude detection technology. For high-frequency vibration, coarse and fine composite shaft control technology can be used.

\subsection{Space adaptation technology of components}

In general, the space environment will directly affect every component in the space laser communication system. The main influencing factors are vacuum environment, cold black environment, background light radiation, particle radiation and space plasma, which will directly affect every component in space laser communication system, which is analyzed from optical surfaces and mechanical structures, electronics and optoelectronic devices respectively.

For optical surfaces and mechanical structures, the technical difficulty lies in the mirror surface performance protection technology, so the solution is to use high-performance radiation-proof materials for the mirror. The mating material which is not prone to cold welding shall be selected for the mechanical component. Then for electronics and optoelectronic devices, the technical difficulty lies in preventing the output power of the laser light source from falling, and suppressing the attenuation of the amplifier gain. The solution is to use a seed light source with strong radiation resistance, adopt an anti-static design for the circuit and the electronic device, and also need to strengthen the circuit and the electronic device.

\section{Conclusion}

At present, key technologies of space laser communication mainly include high-quality optical system design technology, high-precision capture alignment tracking technology, compensation technology influenced by atmospheric channel, high-speed and high-power launch technology, high-sensitivity and low-error detection technology, one-point to multi-point communication technology, platform vibration and compensation technology, and space adaptation technology of components, which can provide reference for relevant personnel.

\section{Acknowledgements}

Fund project: Project at university level of East China Jiaotong University. Project Name: 
Reform on Physics Experimental Teaching Model in Applied Technology University. Project No. XJJG2017-8.

\section{References}

[1] Meng Qingzhe. Research on Development and Application of Laser Communication Ranging [J]. China New Telecommunications, 2018(05).

[2] Jiang Lun, Li Na, Fu Qiang, Wang Chao, Liu Zhuang, Li Yingchao, Zhang Lizhong, Jiang Huilin. Application of One-point to Multi-point Free Space Laser Communication Technology in Formation Flying Constellation [J]. Journal of Changchun University of Science and Technology (Natural Science Edition), 2016(06).

[3] Wang Zhihui, Yang Kang, Xie Huizhong. Laser Communication Tracking System Based on Kalman Filtering [J]. Laser Journal, 2016(12).

[4] Guo Shubiao. Current Status and Application of Satellite Laser Communication [J]. Telecom World, 2017(02).

[5] Li Jun. Satellite Laser Communication Equalization Design Based on Decision Feedback Equalization Technology [J]. Laser Journal, 2017(02).

[6] Zhong Wenfa, Huang Wenxiong, Huang Jiaxing. Current Status and Development Trend of Satellite Laser Communication [J]. China Strategic Emerging Industry, 2017(12).

[7] Wu Ruijing. On Current Status and Development Trend of Satellite Laser Communication [J]. Electronics World, 2017(10).

[8] Guo Wenwen. Automatic Control of Current Drive in Semiconductor Laser Communication [J]. Microelectronics \& Computer, 2017(08).

[9] Qu Zheng, Tong Shoufeng, Dong Yan, Yu Xiaonan, Zhang Min. Design and Verification of Load Coarse Tracking Loop of Satellite-Ground Link Laser Communication [J]. Laser \& Optoelectronics Progress, 2017(07).

[10] Li Xingpei, Sun Xia. Research on Parallel Channel Scheduling in Fiber Laser Communication [J]. Laser Journal, 2017(09). 